\title{
Inclusion Through Political Participation, Trust from Shared Political Engagement: Children of Migrants and School Activism in Italy
}

\author{
Federico Farini ${ }^{1}$
}

Published online: 7 January 2019

(C) The Author(s) 2019

\begin{abstract}
This contribution presents the results of four researches with young migrants that took place in Italy between 2006 and 2014. The four research projects were concerned with the promotion of young people's personal narratives to support a phenomenological description of their semantics of social participation. The researches cover a period characterised by economic crisis, the rise and fall of xenophobic political parties and a continuing debate around migration and inclusion in different social contexts. Data consists of young migrants' narratives, promoted and collected in 62 focus group and 118 individual interviews. The discussion will introduce 'school activism' as the context of participation in political movements and campaigning of young migrants. School activism is an example and the context of the development of trusting relationships with peers, where positions of marginalisation are rejected and identities are negotiated and co-constructed around the person through dialogue. Participants' narratives suggest that cultural essentialism can generate important problems of ineffective educational treatment of cultural identity. These problems can become particularly relevant during adolescence, an age in which the construction of identity may be seen as challenging. At the same time, young migrants and children of migrants' narratives construct identities that through school activism position their authors at the center of rich networks of political participation and peer relationships.
\end{abstract}

Keywords School activism · Categorical inequalities $\cdot$ Children of migrants $\cdot$ Secondary education $\cdot$ Trust $\cdot$ Narratives $\cdot$ Italy

Federico Farini

federico.farini@northampton.ac.uk

1 Department of Sociology, University of Northampton, University Drive, Northampton NN1 $5 \mathrm{PH}, \mathrm{UK}$ 


\section{Introduction}

While entering into a secondary school in Modena, an affluent city in the North of Italy on the verge of a still unforeseen economic crisis, I was overwhelmed by excitement and fears. It was my first experience as a professional researcher, the task being to interview young migrants, promoting narratives about their social networks in and out of the school. Previous experiences suggested me that adolescents might be reluctant in narrating personal experiences; however, human interaction often surprises expectations: I cannot remember a single interview being anything else than an intelligent and provocative discussion on education, politics and peer groups. The researcher and the students, we were sharing and co-constructing personal narratives through multicultural dialogue, while learning that social research is an opportunity to have our voices heard.

This contribution presents the results of that research with young migrants, and four others. All researches took place in Italy between 2006 and 2014, over an unfinished economic crisis, the rise and fall of xenophobic political parties and a continuing debate around migration and inclusion in different social contexts.

\section{The Researches and Methods}

Data consist of young migrants' narratives, promoted and collected in 62 focus group and 118 individual interviews. The participants in the researches were 17 to 20 years old at the moment of data collection and resident in Italy for more than 1 year. An exception is represented by the researcher, an Italian citizen in his late twenties and thirties at the time of the researches.

The first research project was part of a social intervention, Intendiamoci (2006), aimed to promote young people (migrant and Italian) perspectives on their social networks and experiences in multicultural classrooms, using photographs taken by them as the starting point of personal narratives. Although the research was not specifically focused on political participation, the narratives produced revealed the importance of political activism for young migrants attending vocational programmes in the City of Modena. Intendiamoci consisted of 8 focus groups and 21 individual interviews that took place in the classrooms.

The second research project was an evaluation of another social intervention, COMICS (Children Of Migrants Inclusion Creative Systems), funded by the European Commission within INTI04 Call For Projects (Farini and Iervese 2006). COMICS aimed to promote participants' social and political participation, using visual art as a medium for young migrants' expression. The evaluative research was aimed to measure the impact of the project through the promotion and analysis of young migrants' narratives. The sample consisted of 12 focus group and 24 individual interviews at the youth centers where COMICS activities were undertaken.

The third research was interested in young people's narratives, to explore through such narratives their semantic of political participation. The research project, entitled Ri-Generazioni (Re-Generations, 2008-2011) was supported by the Scandicci Town Council (Tuscany), and consisted of 18 focus groups and 48 individual interviews, taking place in youth centers managed by the Scandicci local authority as well as in Secondary Schools. Ri-Generazioni was not designed to specifically work with young migrants who represented a relatively small fraction of the participants. Nevertheless, 
the research allowed to collect personal narratives from young migrants beside the voice of young Italians.

The fourth research was not primarily interested in political participation; rather, it aimed to explore narratives of the self of young people who, at the moment of the interviews, were not employed, in education or in training. As for Intendiamoci, the research, 'A sociocultural analysis of risk, trust and affectivity in young people groups' (risk/trust, 2012-2014) was not specifically addressed to migrants specifically. However, the data produced through 24 focus groups and 25 individual interviews, again taking place in youth centers in the Region Emilia-Romagna, included the voice of young migrants.

Two different non-probabilistic sampling methods were used in the researches. The first one was purposive sampling, which was used for the two evaluations of social interventions. Both evaluative studies were therefore limited only to young people who were involved in the projects. The second sampling method was convenience sampling, used in two studies targeted to young people within delimitated areas. For those researches, subjects meeting the selection criteria (employment status and age for one research, age only for the other) were approached in collaboration with local social services, and their inclusion depended on their willingness to be interviewed.

From the brief descriptions provided, it is apparent that the four researches pursued different aims, and focused on an array of social issues. It is also true that the four researches stretch over almost a decade characterised by relevant economic and political changes in Italy. Finally, the researches took place in different locations that, although for many aspects share economic vocation and political history are nevertheless different. However, all researches share a methodological choice, that is, to consider young people's narratives as a pivotal resource to allow a phenomenological description of the semantics of social participation.

Narratives are conceived as social constructions, in which the observed reality is interpreted and presented at once through series of stories that express knowledge and constitute the context for the production of knowledge, including knowledge about the self. In the context of the four researches, and in line with previous research on the narrative construction of identities from young people experiencing transnational migrations (Amadasi and Iervese 2018), the production of narrative is approached a form of agency towards the construction and negotiation of identities through personal stories this interactional production of narratives highlights the participants' identities (Bamberg 2011). In particular, two types of narratives appear to be tightly intertwined in the production and socialisation of identities through stories: (1) narratives of personal life concern pivotal events that define personal biographies underpinning and (2) narratives of the self, concerning opinions, emotions and relationships (Somers 1994).

Narrative analysis is an extension of the interpretive approaches within the social sciences. Narratives lend themselves to a qualitative enquiry in order to capture the rich data within stories. Narrative analysis takes the story itself as the object of study; thus, the focus is on how individuals or groups make sense of events and actions in their lives through examining the story they produce (Riessman 1993). This approach to study is not new to qualitative sociology. Sociology has had a history of ethnographic study including the analysis of personal accounts. However, with ethnography, it is the events described and not the stories created that are the object of investigation: language is viewed as a medium that reflects singular meanings. 
Under the narrative movement and criticisms of positivism, the question of textual objectivity has been challenged by social constructionism (Gergen 1997), encouraging many to approach narratives as social constructions, that are social in the sense they are exchanged between people. Narratives constitute rather than represent reality (Fisher, 1987). As such, life stories are a linguistic unit involved in social interactions and are therefore cultural products, in their content and form (Linde 2001). Language is therefore seen as deeply constitutive of reality, not merely a device for establishing meaning. Stories do not reflect the world out there, but are constructed, rhetorical and interpretive (Riessman 1993), lending themselves to a phenomenological analysis.

Linde's concept of life stories as cultural products and Riessman interactive rhetoric inform the methodology of all four researches, allowing to approach interviews as a (multi)cultural product of a dialogue co-constructed and continuously re-interpreted by the researcher and the participants.

The narrative approach to the analysis of interviews applied in the four investigations hereby presented is posited to have the ability to capture social representations 'in the making'. Narrative analysis is well suited to study subjectivity and identity largely because of the importance given to imagination and the human involvement in constructing a story, allowing an analysis of how culturally contingent and historically contingent the terms, beliefs and issues narrators address are (Rosenwald and Ochberg 1992; Riessman, 1998; Gill 2001).

Participant narratives across all four research projects were promoted dialogical forms of communication, acknowledging that participants in social research actively construct meanings and social practices, influencing the cultural and social situations in which they are involved (James et al. 1998; Baraldi and Iervese 2012). Inspired by Mercer and Littleton (2007) research on dialogic teaching, dialogic research is defined here as that in which all participants make substantial and significant contributions and through which thinking or themes are promoted to move forward, and through which researcher and participants mutually encourage each other to participate actively. Dialogic research requires facilitation of interaction, in which the researcher is an organiser of participation, and mutual learning (see Holdsworth 2005). Facilitative dialogic research is a specific form of social research based on methodologies of facilitation.

The practice of facilitation emphasises the production of different perspectives, in displaying and managing predefined assumptions, doubts, divergent interpretations, different stories and experiences, unpredicted emotions. Facilitation enhances and manages different perspectives. In interactions generated by social research, facilitation makes it possible to coordinate and manage active participation and relationships and promote mutual learning-outcome through post-activity feedback and reflection.

\section{Results and Discussion}

Narratives produced by young migrant converge in suggesting the criticism of the idea of cultural identity as an 'essential' identity, something given and fixed (Hofstede 1980; Ting Toomey 1999). The researches presented in this contribution support a different theoretical claim, underpinned by social constructivism, advancing the idea that cultural identity is negotiated in public discourse and interaction (Baraldi 2009; Holliday 2011; 
Piller 2010; Zhu Hua 2014). Data collected in the four social research projects invite us to consider political participation as a crucial context of the construction of cultural identity through social practices.

In this contribution, an English rendition of the original narratives in the Italian language will be provided, aiming to reproduce participants' linguistic choices and style. Excerpts from the narratives co-constructed by the researcher and the participants will be used to support the discussion of data. The discussion that follows should not be understood as an attempt to distill some cultural characteristics of young migrants as a social group; rather, the aim of this article is to discuss how narratives present and propose forms of personal identity as well as the meaning of interpersonal relationships. In line with its methodological premises, this contribution approaches personal narratives as constructed through multicultural dialogue, that is, a social process rather than an object.

\section{Marginalisation in the Education System}

Participants' narratives emphasise the importance of agency in the construction of the meaning of their social experiences. Agency is observed when individual actions are not considered as determined by another subject (James 2009; James and James 2008; Baraldi 2015), although the concept of agency implies that individuals ' ... interact with the social conditions in which they find themselves' (Moosa-Mitha 2005: 380), acknowledging limitations imposed by social constraints (Bjerke 2011; James 2009; James and James 2008; Moosa-Mitha 2005; Valentine 2011; Wyness 2013).

Agency and its social conditions are visible in social interactions (Bae 2012; Baraldi 2014; Bjerke 2011; Harre' and Van Langenhove 1999), where agency can be observed in the availability of choices of action and the agent's possibility to exercise a personal judgement and to choose according to it (Dahlberg and Moss 2005; Markstroem and Halldén 2009; Moss 2009).

In the data sets considered, participants' narratives present a situation of limited agency in the education system. This is not surprising, as a tradition of sociological research on education points out that education is interested in standardised role performances, rather than agency (Parsons and Bales 1955; Sinclair and Coulthard 1975; Mehan 1979; Vanderstraeten 2004; Farini 2011; Walsh 2011; Luhmann 2012). The following excerpt is taken from the Intendiamoci research; a student from migrant background is sharing a narrative that represents a form of categorisation.

\section{Modena, Intendiamoci, December 2006}

School is the most difficult thing, because if you have problems, then you see that they really expect you to have problems; before you start because you come from a different place. A bad assignment and you are in need of support, but this is not the same for Italian students. They are told to study more, not that they need support, in a way that it is up to them, not up to support they receive, which is somehow more respectful

Irrespectively of their individuality, migrant students are categorised as members of a problematic group; such membership informs their position in the education system 
and the interpretation of their contributions. The language used to convey the narrative, and in particular, the distinction respect/lack of respect indicates that the student perceives the ethnic-based categorisation as a negation of his agency.

Tilly's idea that inequality becomes embedded in any organisational structure (Tilly 1998) may help in further analysing this interesting aspect of participants' narratives. Tilly (1998) elaborates an inventory of causal mechanisms through which categorical inequality is generated and sustained. Tilly (ibid) argues that certain kinds of social structural relations are solutions to problems generated within social systems, for instance the problem of trust. Educational interaction creates, through selective events, categorical forms of inequality. Durable, categorical distinctions make easier to know who to trust and who to exclude, and categorical inequalities become stable features of organisation, enhancing the stability of educational relationships. In education, inequality among individual performances and goal attainment is a structural feature of social relationships and an expected output of the system. Tilly (1998: 15) distills the core explanation of categorical inequality to three positions:

1) Organizationally installed categorical inequality reduces risks. Categorical inequalities sustain in the risky choice to accord or not trust. This is a claim about the effects of categorical inequality on the stability of organisational relationships: the former stabilises the latter;

2) Organisations whose survival depends on stability therefore tend to adopt categorical inequality. This is a selection argument: the functional trait, categorical inequality, is adopted because it is functional,

3) Because organisations adopting categorical inequality deliver greater returns to their dominant members and because a portion of those returns goes to organisational maintenance, such organisations tend to crowd out other types of organisations.

For educational organisations, the limitation of risk offered by institutional distrust frees resources for the attainment of curricular goals via the exclusion of categories of students. In educational situations, categorical distinctions stabilise social relationships, but also positions of marginalisation (with regard to migrant students, see Devine 2013). Institutional trust and institutional distrust may be understood as consequences of the operations through which educational organisation reproduce themselves. The two following excerpts illustrate Tilly (1998) theory: categorical inequalities contribute to the stabilisation of marginalisation.

\section{Piacenza, Risk/Trust, June 2013}

I feel that teachers genuinely want migrants to succeed, but they are anxious because they have this idea that migrants have problems and it is enough to be a bit slower that they run around asking for help and you are not seen as the same as others anymore. But maybe you just need time. This makes it hard you may learn Italian but you do not feel like part of the school as the others. Also because when it is said that you need support no one can see what you can do already: you become a preoccupation. 


\section{Cesena, Risk/trust, June 2013}

I used to study at the Liceo (selective school), this is what my parents fancied, I suppose. They had that idea that Liceo is for future medical doctors. However, after a single month teachers told me 'fine if you stay with us to listen, but maybe it is better to look for a different school'. This was because it was decided that I was not going to pass. They said that I was showing issues but I think that really the issue was because I am a migrant and they are quick to see you as a failure after just one bad month, because this is what they expect you to do, to fail because you are like that. I was determined to achieve, leaving was no choice of mine

The narratives promoted in the researches presented here introduce another form of marginalisation that does not concern the educational careers of migrant students but their access to contexts of personal affective relationships, which is an important aspect of the school experience. The following expert taken from the COMICS research can support a discussion of this form of marginalisation.

\section{Modena, COMICS, January 2008 (Focus Group)}

Josie: I am doing quite well at school, well I am getting better, but still I feel isolated and unhappy

Researcher: Do people exclude you?

Josie: No one really does, the system does. They push you back as they think that you are not quite there with guys of your age because of the language, basically

Researcher: Push you back?

Josie: Back to a classroom with children that are younger, even three years younger. They are CHILDREN. Of course they do not fancy you and you think they are a bit, boring, so to speak. You feel quite alone for the many hours you spend at school

Rita: You may develop language while doing easy stuff with children, but you are left behind with friendship. I feel embarrassed with friends outside, I have only children's antics to share, after a while it is not funny

Research suggests that classrooms are contexts of peer relationships based on affectivity and personal choices, that can be therefore observed as expression of agency (Patrick et al. 2007; Farini 2008; Baraldi and Iervese 2014). Participants' narratives clearly present semantics of the classroom as a context of peer-socialisation and expression of agency. However, they experience unfavourable conditions for developing interpersonal relationships at school, due to educational strategies aimed to support academic achievement, but detrimental for their inclusion in the peer-groups.

Removed from their age group at school (being pushed back, in the vocabulary of Italian school practices), young migrants experience reduced opportunities for agency: personal affective relationships are simply not viable with much younger classmates. The pedagogical strategy deployed to allow young migrants to familiarise with the education system and to develop linguistic competence at a slower pace, supports a 
process of marginalisation from what participants see as the 'proper peer groups', such marginalisation can be understood as a latent function of the manifest functions (support of development) of education. As suggested by Deleuze and Guattari (1987), enlightened practices can deny the dignity of self-determination, objectivising certain subjects.

\section{From Marginalisation to the Invention of New Forms of Inclusion: School Activism}

Another social system where participants' position is located at the margins is the political system. Participants' narratives concerning inclusion in the political system develop around their distrust in the concrete possibility of agency, connected to their citizenship status. It is possible to utilise the concept of agency presented in paragraph 1 as a conceptual tool to understand the position of young migrants. Whilst young migrants can make political autonomous choices, such choices are not visible in the political system, due to a limited access to political rights. This prevents their preferences to make a difference. Using Bateson's vocabulary (Bateson 1972), the informative value of young migrants' internal difference (their political preference) for the political system is nullified by exclusion from political rights. This short excerpt from the COMICS research illustrates the divergence between personal engagement and lack of agency due to the citizenship status.

\section{Modena, COMICS, February 2008}

Politics is like football for me, I pick my team, I watch, I get angry if a team I hate wins, but I will be never good enough to play, because I am not good enough, I am no citizen.

Taylor's (1989) historical account of the conceptualisations of human value may support a discussion on the above excerpt, which represent a common form of representation in participant's narratives. According to Taylor (ibid.), in hierarchical societies human value was ranked against the proximity to the owner of the land. Examining the transition from feudal societies to societies based on trade in Western and Southern Europe, Taylor (ibid) observes a semantic evolution, whereas human value is a function of dignity, which is taken to be both the possession of, and what it is owed to, each and every individual, regardless of the conditions of their birth.

However, human value as a structural form does not disappear in trade societies; in order to differentiate grades of human value, the universal and inclusive principle of dignity is coupled with the selective and exclusive principle of 'level of development', which is measured according to separateness from others, self-governance and independence from the claims, wishes and command of others. While Taylor (ibid.) suggests that the function of the combination of development and dignity is to detect a shared quality among aristocracy and bourgeoisie, that would otherwise be separated by degrees of honour, such coupling has been the catalyst for semantics of categorical distinction: development is associated with general historical movement (savages against civilised), personal development (child against adult), gender (female against male), ethnicity (black people against white people, white people of the south against white people of the north). 
The coupling between dignity and development is still accepted in the public discourse only regarding generational order (although being the object of criticism, particularly from the area of childhood studies (Wyness 2014; Leonard 2016). However, its underpinning structure, that is, the coupling between the inclusive principle of dignity and an exclusive principle still generates social semantics. An example of this consists in the coupling between dignity and assumed limited school readiness in migrant students (Herrlitz and Maier 2005; Grant and Portera 2011), or in the coupling between agency and citizenship status within legal and political systems. The following expert is taken from the Ri-Generazioni research, part of a narrative shared by a migrant young man.

\section{Scandicci, Ri-Generazioni, May 2010}

I think that if rights are also about what you can potentially do, maybe you won't but you are not prevented, I mean offering you possibilities, I do not have rights. Or I have less than Italians in Italy. I cannot vote or I can dream of changing the town but I cannot really as I will never be a candidate. Unless I change myself and become Italian in the passport, but this would be like changing to have rights that others have for what they are

A discussion of the narratives represented by the above excerpt may develop from the ideas that whilst dignity generates inclusive and universal human rights, citizenship generates exclusive and conditional personal rights (Mattheis 2012). The multicultural dialogue co-constructed by the researcher and the participants indicates that young migrants position themselves at the centre of the paradoxical coupling between dignity and citizenship. The two excerpts shown below, from 2006 and 2013, suggest the persistence of marginalisation and inequality in young migrants narratives concerning their political participation.

\section{Modena, Intendiamoci, December 2006, Focus Group}

Nicu: At the end of the day I am not really anyone while I feel quite secure about who I am and what I like.

Researcher: What do you mean?

Nicu: I am not Romanian, well I am but I do not live like one, I live like an Italian, but I am not.

Amadou: I am really into politics, I just do not understand the guys who do not care, which is stupid because it is like one who does not care about his body and illness, illness and politics that affect your life. I spend lots of time watching all the debates and shows with politicians and when I go to the Internet Café it is not only a movie but also political news, and international. But while I think it is serious stuff, then I also realise that it is not, because I cannot do much with all of my information, I cannot vote or being a candidate. So it is like a game really if you cannot be of it, and I am not sure if am not wasting my time as the guys who play with NES or Playstation

Paulo: I made up my mind a lot of time ago about politics but I cannot choose in practice, I have no choice but I would know what to choose 
Scandicci, Ri-Generazioni, May 2009

My idea is that one thing is the passport, another thing is who you are. Because of the passport I am still a guest, a kind of visitor, but I do not feel like one. What are my interests when being heard and to do things here, so I think I am not the data in the passport but the person in the photograph, who wants to be part but cannot as others can. It is a struggle.

These narratives suggest that young migrants do not experience the negation of their human rights, but the exclusion from 'personal rights', therefore the exclusion from some social domains. The conditional access to personal rights is exemplified by the exclusion from political rights. While the semantics of rights is based on the dogmatic of human dignity (Teubner 1988, 2010), human dignity that does not presuppose human essence; on the contrary, it is the individuality of persons that is constructed in the social sphere by help of rights.

Two sets of stories concerning positions of marginalisation emerge from young migrants' narratives. The first set of stories regard the consequences of categorical inequalities structuring the operation of the education system. The second set of stories refers to limited agency in the political system due to exclusion from personal rights.

The construction of categorical inequalities in education activates a vicious circle between institutionalised distrust and marginalisation (Luhmann 1988). For Luhmann (ibid.), while trust enlarges the range of possible actions in a social system, distrust restricts this range, in that it requires additional premises for social relationships, which protect interactants from a disappointment that is considered highly probable. When distrust is established, building trust appears very difficult because the interaction is permeated by trust in distrust.

Marginalisation in the education system hinders peer-relationships. In particular, removing young migrants from their age group at school and placing them in a younger cohort prevents the construction of person-centred relationships and trust based on affectivity. Similar alienating consequences can be enhanced by the exclusion from political rights. Marginalisation in the political system generates trust in distrust regarding the possibility to access forms of active citizenship and political agency. Experiences in the education system and experiences in the political system converge to the positioning of young migrant in a situation of marginality.

However peer-relationships and political agency are not necessarily the two forces that push young migrant in a downward spiral of isolation and disempowerment. The narrative collected also suggest that peer-relationships and political agency are sometimes intertwined in situations when political activism becomes the context for the development of positive peer-relationships which in turn extend the meaning of political activism to an opportunity for the creation of mutual trust commitments as members of politically active groups. This is suggested by the excerpt below, from the COMICS research.

\section{Modena, COMICS, March 2008}

I was feeling isolated and really sad for a while, and angry because I was feeling I was not listened to at school and not be quite like the others outside. It has been quite bad recently; because of the elections I really wanted to be heard but I knew 
I am no citizen of Italy. Then I see the French guys get out in the street, for the right to a decent job. They are not really touched because they are still students, but they want to make a difference for the people in the here and now. And I realised that you do not need to vote to do it. When it was the students' strike I just joint the guys of the strike because here is not different from France. I do not feel out of place when we have meeting. I want to join a Union because it is what you want for the future that matters not where you come from

The excerpt introduces a social process emerging from many narratives that can be discussed by making use of the concept of unintended consequence. Merton (1957) analyses types and determinants of unanticipated consequences of purposive action. For Merton (ibid.) the functions of a social practice are its 'observable objective consequences'. Manifest functions are those outcomes that are intended and recognised by the agents concerned; latent functions are those outcomes that are neither intended nor recognised. Although the distinction between manifest and latent functions has been the object of critical review (Campbell 1982; Portes 2000; Farini 2012), the concept of unintended consequences can help understanding participants' narratives.

Categorical forms of inequality set in motion a pattern of contradictory effects. Participants' personal narratives suggest that in some circumstances, rather than alienation the exclusion from political rights generates political participation and the access to forms of political activism that represents the context for the experience of trust commitment and interpersonal relationships.

Although presenting conditions of distrusts and marginalisation, participants' narratives also invite to reflect on of the building of trust within situations of school activism. In particular, the narratives collected during the four researches relate school activism to Kelman (2005) model of trust building. Kelman (ibid.) analyses conditions of radical distrust and building trust in workshops involving Israeli and Palestinian representatives trying to reach peaceful agreements. Kelman (ibid.) argues that in these workshops trust was built through successive approximations of increasing degrees of commitment, starting from the building of a feeble temporary trust (working trust) not committing participants to anything beyond the solution of specific problems. Two excerpts help illustrating this process, taken from the COMICS research and Ri-generazioni.

\section{Modena, COMICS, November 2008}

There is a lot to do, because you know we are not many, and you do want as many students as possible attending the debate but also that they understand the meaning of it, not only the free time to smoke and drink. I got friends almost without speaking, just doing things which made sense to all. And another thing is that I understand and master the meaning of my actions and I feel this is reckoned as they trust me as I trust them. I have showed skills and trustworthiness.

\section{Scandicci, Ri-Generazioni, May 2010}

What I am excited about all those strikes and protest in the street to save the school against privatisation is that I am not 'someone in deficit' anymore. I am 
not the struggling one to be helped, but I can help with my thoughts and practical actions. Actually, I was not friend with any of the guys in the political group. I was working with them before befriending them. You walk in the streets with people you do not know well, but also you know them well in the sense that they share what you want for the future. Of course, then you become friend with some, actually a good friend and there is something more than befriending someone at the disco. Fun is part of the friendship but really it is what you want from the future that make you feel closer politically and in a personal sense.

In Kelman (ibid.) model, working trust and interpersonal relationships can merge, but only at a later stage of the interaction. Interpersonal closeness is not the basis of (working) trusting commitment. However, interpersonal closeness may follow working trust.

The two excerpts represent a diffused aspect of the narratives collected over almost 10 years: forms of school activism are the context for the development of working trust through political participation and involvement in activities with peers. Working trust creates the presupposition for trust based on affectivity. Data suggest that working trust supports the visibility of political choices, and the development of personal relationships.

\section{Conclusion}

Rather than a small-scale reproduction of political rights they are excluded from, young migrants' involvement in political activities in schools is the context for the development of working trust, built on mutual interests and orientated to specific limited objectives. The final series of excerpts illustrates this point:

\section{Piacenza, risk/trust, June 2013, Focus Group}

Michail: I met my girlfriend while preparing the solidarity march for Greek students. But this is not because I joined the group looking for girls, it just happened

Giga: This is something that you (the researcher) make me thing about. Why the same people see you as a failure at school and give you responsibilities in the (political) group? My idea is that here you are known for what you do. You are what you really do, not what you are supposed to be.

Toni: We all know that the problem at school is that they look for easy solution. If I come from Albania and don't do well, this is because I need to adapt quicker. Maybe there are other reasons, the same as Italians who struggle more than me. But you are another struggling Albanian.

Giga: I think it was the same for his girlfriend who is Italian and because they work together for the political group, she saw he is not an unfortunate.

Working trust may be the foundation of personal relationships, adding a new dimension to the semantics of political participation of young people. This new dimension consists in (re)-inclusion based on dialogue, a genuinely social process beyond the centrality of individual agency emphasised by previous research (Percy-Smith 2010; Tholander 2011). 


\section{Modena, Intendiamoci, December 2006}

I think that soon everyone who lives in the country will be able to vote for a candidate, which makes sense as we all live and share issues and hopes with Italians. But this is not really the point, I understand now. I used to hate Citizenship Education, because it is about rights I do not have. But I understand now, and the guys and the workshops and the professor from the University coming and taking about anarchism helped... he thing is not having rights, citizenship is about doing it, doing the citizen. This is what I am, a 'maker', we all are.

\section{Modena, risk/trust, June 2013}

I cannot be happier than when I am not a Moroccan anymore. It is like being born again, and I think it is the same for the Italian guys there and here. Not you are because you come from but you are something different each time, you are the cause you are fighting for.

Young migrants experience marginalisation in the education system and in the political system. We have seen that young migrants' narratives present a link between educational practices and a concept of cultural identity as an 'essential' identity, given and fixed (Hofstede 1980; Ting Toomey 1999). The same narratives show that cultural essentialism can generate important problems of ineffective educational treatment of cultural identity. These problems can become particularly relevant during adolescence, an age in which the construction of identity may be seen as challenging (Fail et al. 2004).

However, the narrative constructed through the four researches presented in this article, also suggest a successful construction of identities through social interactions, in the face of adversative conditions (Bamberg and Georgakopoulou 2008). The narratives collected present a series of self-histories (Nelson 2003) that are enshrined in shared histories (Norrick 2012) referred to group memberships, as previously observed by Baraldi and Iervese (2017) regarding narratives of memory and identity in multicultural classrooms.

The self- and shared histories that compose the narratives presented by the participants in the researches refer to the importance of trust which develops gradually based on the experience of shared political engagement. School activism' describes a situation where student's political movements and campaigning can become at once the contexts of active political participation of young migrants and the contexts of the developing of personal relationships. The multidimensional nature of schools activism explain the continuing interlacements between narratives of personal life and narratives of the self (Giddens 1990, 1991)characterising young migrants' contributions: narratives of emotions and relationships are intertwined with narratives of events and experiences concerning political participation.

Young migrants' narratives present school activism as the context for the construction of identities and the development of networks that represent a form of social capital. As a product of contingent situations, the narratives promoted through interviews or focus groups cannot be understood as a structural component of young 
migrants' personalities (Holliday 2011). However, such narratives invite to tune in the voice of young migrants to observe them as agents who tell stories that talk of active rejection of positions of marginalisation in the political system.

Open Access This article is distributed under the terms of the Creative Commons Attribution 4.0 International License (http://creativecommons.org/licenses/by/4.0/), which permits unrestricted use, distribution, and reproduction in any medium, provided you give appropriate credit to the original author(s) and the source, provide a link to the Creative Commons license, and indicate if changes were made.

Publisher's Note Springer Nature remains neutral with regard to jurisdictional claims in published maps and institutional affiliations.

\section{References}

Amadasi, S. and Iervese, V. (2018). The right to be transnational: narratives and positionings of children with a migration background in Italy. In C.Baraldi \& T.Cockburn (eds.). Theorizing Childhood, 239-262.

Bae, B. (2012). Children and teachers as partners in communication: focus on spacious and narrow interactional patterns. International Journal of Early Childhood, 44(1), 53-69.

Bamberg, M. (2011). Narrative practice and identity navigation. In J. A. Holstein \& J. F. Gubrium (Eds.), Varieties of narrative analysis (pp. 99-124). London: Sage.

Bamberg, M., \& Georgakopoulou, A. (2008). Small stories as a new perspective in narrative and identity analysis. Text \& Talk, 28, 377-396.

Baraldi, C. (Ed.). (2009). Dialogue in intercultural communities. From and educational point of view. Amsterdam/Philadelphia: John Benjamin.

Baraldi, C. (2014). Children's participation in communication systems: a theoretical perspective to shape research. Soul of Society: A Focus on the Live of Children and Youth, 18(18), 63-92.

Baraldi, C. (2015). Promotion of migrant children's epistemic status and authority in early school life. International Journal Of Early Childhood, 47(1), 5-25.

Baraldi, C., \& Iervese, V. (Eds.). (2012). Participation, facilitation, and mediation. Children and young people in their social contexts. London/New York: Routledge.

Baraldi, C., \& Iervese, V. (2014). Observing children's capabilities as agency. In D. Stoecklin \& J. M. Bonvin (Eds.), Children's rights and the capability approach. Challenges and prospects (pp. 43-65). Dordrecht: Springer.

Baraldi, C., \& Iervese, V. (2017). Narratives of memories and dialogue in multicultural classrooms: new challenges. Narrative Inquiry, 27(2), 398-417.

Bateson, G. (1972). Steps to an ecology of mind: collected essays in anthropology, psychiatry, evolution, and epistemology. San Francisco: Chandler.

Bjerke, H. (2011). It's the way to do it. Expressions of agency in child-adult relations at home and school. Children \& Society, 25(2), 93-103.

Campbell, C. (1982). A dubious distinction: an inquiry into the value and use of Merton's concepts of manifest and latent function. American Sociological Review, 47(1), 29-43.

Dahlberg, G., \& Moss, P. (2005). Ethics and politics in early childhood education. London: Routledge.

Deleuze, G., \& Guattari, F. (1987). A thousand plateaus: capitalism and schizophrenia. Minneapolis: University of Minnesota Press.

Devine, D. (2013). Valuing children differently? Migrant children in education. Children and Society, 27, 282294.

Fail, H., Thompson, J., \& Walker, G. (2004). Belonging, identity and third culture kids. Life histories of former international school children. Journal of Research in International Education, 3(3), 319-338.

Farini, F. (2008). Paths of hybridization through the invention of new cultural forms. In M. Gottwald, M. Klemm, \& B. Schulte (Eds.), KreisLäufe - CircularFlows. Kapillaren der Weltkultur - Capillaries of World Culture (pp. 155-171). Muenster: LIT.

Farini, F. (2011). Cultures of education in action: research on the relationship between interaction and cultural presuppositions regarding education in an international educational setting. Journal of Pragmatics, 43, 2176-2186. 
Farini, F. (2012). Affectivity, expertise, and inequality: three foundations of trust in education. Reflections on presuppositions, (unintended) consequences, and possible alternatives. In A. Mica, A. Peisert, \& J. Winczorek (Eds.), Sociology and the unintended. Robert Merton Revisited (pp. 155-167). Frankfurt a.M: Peter Lang.

Farini, F., \& Iervese, V. (2006). La ricerca qualitativa. In B. Pezzotta (Ed.), Children of Migrants Inclusion Creative Systems Project (pp. 157-191). Modena: Comune di Modena.

Fisher, W. R. (1987). Human communication as narration: toward a philosophy of reason, value, and action. Columbia: University of South Carolina Press.

Gergen, K. J. (1997). Who speaks and who replies in human science scholarship? History of the Human Sciences, 10, 151-173.

Giddens, A. (1990). The consequences of modernity. Cambridge: Polity Press.

Giddens, A. (1991). Modernity and self-identity. Self and society in the late modern age. Cambridge: Polity Press.

Gill, P. B. (2001). Narrative inquiry: designing the processes, pathways and patterns of change. Systems Research and Behavioral Science, 18(4), 335-344.

Grant, C. A., \& Portera, A. (Eds.). (2011). Intercultural and multicultural education. Enhancing global interconnectedness. London/New York: Routledge.

Harre', R., \& Van Langenhove, L. (Eds.). (1999). Positioning theory. Oxford: Blackwell.

Herrlitz, W., \& Maier, R. (Eds.). (2005). Dialogue in and around multicultural schools. Tubingen: Niemeyer.

Hofstede, G. (1980). Culture's consequences. Beverly Hills/London: Sage.

Holdsworth, R. (2005). Taking young people seriously means giving them serious things to do. In J. Mason \& T. Fattore (Eds.), Children taken seriously. In Theory, policy and practice. London: Jessica Kingsley Publishers.

Holliday, A. (2011). Intercultural communication and ideology. Thousand oaks/London: Sage.

James, A. (2009). Agency. In J. Qvortrup, G. Valentine, W. Corsaro, \& M. S. Honig (Eds.), The Palgrave handbook of childhood studies (pp. 34-45). Basingstoke: Palgrave.

James, A., \& James, A. (2008). Key concepts in childhood studies. London: Sage.

James, A., Jenks, C., \& Prout, A. (1998). Theorizing childhood. Oxford: Polity Press.

Kelman, H. (2005). Building trust among enemies: the central challenge for international conflict resolution. International Journal of Intercultural Relations, 29, 639-650.

Leonard, M. (2016). Sociology of Children, Childhood and Generation. London: Sage

Linde, C. (2001). Narrative and social tacit knowledge. Journal of Knowledge Management, 5(2), 160-170.

Luhmann, N. (1988). Familiarity, confidence, trust: problems and alternatives. In D. Gambetta (Ed.), Trust: making and breaking cooperative relations (pp. 94-107). Oxford: Department of Sociology University of Oxford.

Luhmann, N. (2012). Theory of Society. Stanford: Stranford University Press.

Markstroem, A.M., \& Halldén, G. (2009). Children's strategies for agency in preschool. Children and Society, $23,112-122$

Mattheis, C. (2012). The system theory of Niklas Luhmann and the constitutionalization of the world society. Goettingen Journal of International Law, 4(2), 625-647.

Mehan, H. (1979). Learning lessons. Cambridge: Harvard University Press.

Mercer, C., \& Littleton, K. (2007). Dialogue and development of children's thinking. London/New York: Routledge.

Merton, R. K. (1957). Social theory and social structure. Glencoe: Free Press.

Moosa-Mitha, M. (2005). A difference-centred alternative to theorization of children's citizenship rights. Citizenship Studies, 9, 369-388.

Moss, P. (2009). There are alternatives! Markets and democratic experimentalism in early childhood education and care. Working Paper 53. The Hague: Bernard Van Leer Foundation.

Nelson, K. (2003). Self and social functions: individual autobiographical memory and collective narrative. Memory, 11(2), 125-136.

Norrick, N. (2012). Remembering for narration and autobiographical memory. Language and Dialogue, 2(2), $193-214$.

Parsons, T., \& Bales, R. F. (1955). Family, socialization and interaction process. Glencoe: Free Press.

Patrick, H., Ryan, A., \& Kaplan, A. (2007). Early adolescents' perceptions of the classroom social environment, motivational beliefs, and engagement. Journal of Educational Psychology, 99, 83-98.

Percy-Smith, B. (2010). Councils, consultation and community: rethinking the spaces for children and young people's participation. Children's Geographies, 8(2), 107-122.

Piller, I. (2010). Intercultural communication: A Critical Introduction. Edinburgh University Press 
Portes, A. (2000). The hidden abode: sociology as analysis of the unexpected. American Sociological Review, 65, 1-18.

Riessman, C. K. (1993). Narrative analysis. Newbury Park: Sage.

Riessman, C. K. (1998). Narrative methods for the human sciences. Los Angeles: Sage.

Rosenwald, G. C., \& Ochberg, R. L. (Eds.). (1992). Storied lives: the cultural politics of self-understanding. New Haven: Yale University Press.

Sinclair, J., \& Coulthard, M. (1975). Towards an analysis of discourse. The English used by teachers and pupils. Oxford: Oxford University Press.

Somers, M. (1994). The narrative constitution of identity: a relational and network approach. Theory and Society, 23(5), 605-649.

Taylor, C. (1989). Sources of the self: the making of the modern identity. Cambridge: Harvard University Press.

Teubner, G. (1988). Autopoietic law: a new approach to law and society. Berlin: de Gruyter.

Teubner, G. (2010). Constitutionalising polycontexturality. Social and Legal Studies, 19, 327-341.

Tholander, M. (2011). Student-led conferencing as democratic practice. Children and Society, 25, 239-250.

Tilly, C. (1998). Durable inequality. Berkeley: University of California Press.

Ting Toomey, S. (1999). Communication across cultures. New York: The Guilford Press.

Valentine, K. (2011). Accounting for agency. Children \& Society, 25, 347-358.

Vanderstraeten, R. (2004). The social differentiation of the educational system. Sociology, 38(2), 255-272.

Walsh, S. (2011). Exploring classroom discourse: language in action. New York/London: Routledge.

Wyness, M. (2013). Children's participation and intergenerational dialogue: Bringing adults back into the analysis. Childhood, 20(4), 429-442

Wyness, M. (2014). Childhood. London: Polity.

Zhu Hua (2014). Exploring Intercultural Communication: Language in Action. London: Routledge 